\title{
Possible Inhibitor from Traditional Chinese Medicine for the $\beta$ Form of Calcium-Dependent Protein Kinase Type II in the Treatment of Major Depressive Disorder
}

\author{
Tzu-Chieh Hung, ${ }^{1}$ Wen-Yuan Lee, ${ }^{1,2,3}$ Kuen-Bao Chen, ${ }^{1,2,4}$ Hung-Jin Huang, ${ }^{5}$ \\ Yueh-Chiu Chan, ${ }^{2}$ Cheng-Chun Lee, ${ }^{2}$ and Calvin Yu-Chian Chen ${ }^{1,2,6,7}$ \\ ${ }^{1}$ Department of Biomedical Informatics, Asia University, Taichung 41354, Taiwan \\ ${ }^{2}$ School of Medicine, College of Medicine, China Medical University, Taichung 40402, Taiwan \\ ${ }^{3}$ Department of Neurosurgery, China Medical University Hospital, No. 2, Yude Road, North District, Taichung 40447, Taiwan \\ ${ }^{4}$ Department of Anesthesiology, China Medical University Hospital, Taichung 40447, Taiwan \\ ${ }^{5}$ Department of Chinese Pharmaceutical Sciences and Chinese Medicine Resources, College of Pharmacy, China Medical University, \\ Taichung 40402, Taiwan \\ ${ }^{6}$ Research Center for Chinese Medicine \& Acupuncture, China Medical University, Taichung 40402, Taiwan \\ ${ }^{7}$ Human Genetic Center, Department of Medical Research, China Medical University Hospital, Taichung 40447, Taiwan
}

Correspondence should be addressed to Cheng-Chun Lee; leeck@mail.cmu.edu.tw and Calvin Yu-Chian Chen; ycc929@MIT.edu

Received 19 February 2014; Revised 5 March 2014; Accepted 5 March 2014; Published 18 June 2014

Academic Editor: Chung Y. Hsu

Copyright (C) 2014 Tzu-Chieh Hung et al. This is an open access article distributed under the Creative Commons Attribution License, which permits unrestricted use, distribution, and reproduction in any medium, provided the original work is properly cited.

Recently, an important topic of major depressive disorder (MDD) had been published in 2013. MDD is one of the most prevalent and disabling mental disorders. Consequently, much research is being undertaken into the causes and treatment. It has been found that inhibition of the $\beta$ form of calcium/calmodulin-dependent protein kinase type II ( $\beta$-CaMKII) can ameliorate the disorder. Upon screening the traditional Chinese medicine (TCM) database by molecular docking, sengesterone, labiatic acid, and methyl 3-O-feruloylquinate were selected for molecular dynamics. After $20 \mathrm{~ns}$ simulation, the RMSD, total energy, and structure variation could define the protein-ligand interaction. Furthermore, sengesterone, the principle candidate compound, has been found to have an effect on the regulation of emotions and memory development. In structure variation, we find the sample functional group of important amino acids make the protein stable and have limited variation. Due to similarity of structure variations, we suggest that these compounds may have an effect on $\beta$-CaMKII and that sengesterone may have a similar efficacy as the control. However labiatic acid may be a stronger inhibitor of $\beta$-CaMKII based on the larger RMSD and variation.

\section{Introduction}

The calcium/calmodulin-dependent protein kinase type II family (CAMKII) has been reported to be related to stress and antidepressant response $[1,2]$. However, a recent paper in science [3] indicates that the $\beta$ form of calcium/calmodulindependent protein kinase type II ( $\beta$-CaMKII) is related to major depressive disorder (MDD).

MDD is one of the most prevalent and disabling mental disorders. Patients suffering from this disorder are characterized by having a pervasive and persistent low mood that is accompanied by low self-esteem, despair, and may go on to develop anhedonia, which manifests as a loss of interest or pleasure in normally enjoyable activities.

Social pressures associated with the recent economic downturn and work pressure may push more and more people to suffer from this disorder. One of the dangers of this mental disorder is that the patient may indulge in self-harm and may even attack or commit suicide.

From the above description, having a drug to ameliorate the emotional state and treat the disorder is important. According to reference [3], an overexpression of $\beta$-CaMKII 


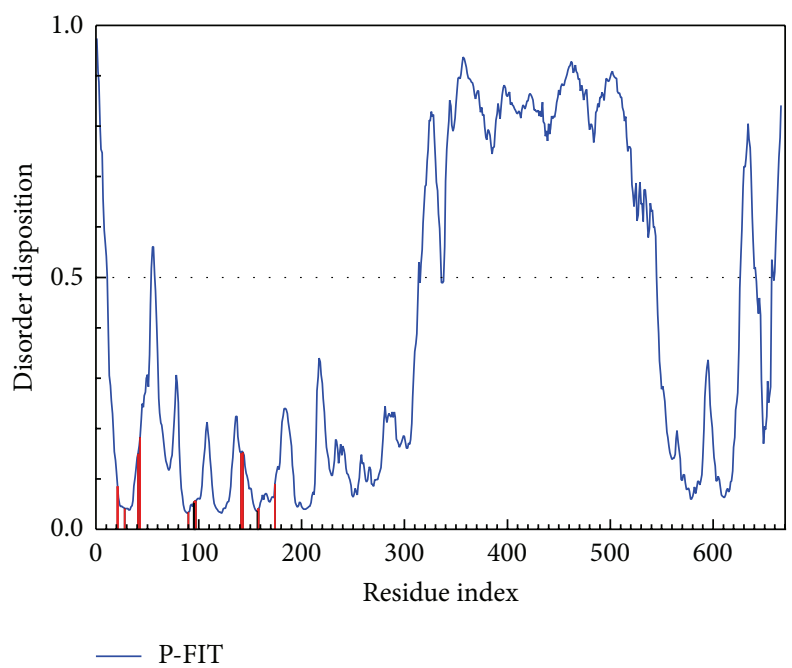

FIGURE 1: The disorder region prediction and binding site detection. The green curve is the disorder disposition of each amino acid, and the red lines are the residues of the important amino acids.

TABLE 1: Screening the TCM database docking to CAMKII.

\begin{tabular}{|c|c|c|c|c|}
\hline Name & Herb & -PLP1 & -PLP2 & Dock Score \\
\hline Sengesterone & Cyathula capitata Moq. & 75.71 & 69.85 & 134.220 \\
\hline Labiatic acid & Rosmarinus officinalis L. & 84.03 & 87.55 & 111.237 \\
\hline Methyl 3-O-feruloylquinate & Phellodendronchinense C. K. Schneid. & 44.46 & 45.03 & 109.576 \\
\hline Serpentine & $\begin{array}{l}\text { Catharanthus roseus (L.) G. } \\
\text { Don./Rauwolfiabeddomei/Rauwolfia } \\
\text { fruticosa/Rauwolfia serpentina }\end{array}$ & 70.29 & 60.45 & 102.18 \\
\hline Flazine & Brucea javanica (L.) Merr. & 62.33 & 62.37 & 101.651 \\
\hline $\begin{array}{l}\text { Xanthotoxol_8-O-beta_-D- } \\
\text { glucopyranoside }\end{array}$ & Glehnia littoralis F. Schmidt ex Miq. & 84.54 & 81.09 & 99.992 \\
\hline Ruine & Peganum harmala L. & 80.96 & 76.7 & 97.767 \\
\hline $3,3^{\prime}, 4$-Tri-O-methyl ellagic acid & Camptotheca acuminata Decne. & 77.81 & 66.18 & 95.091 \\
\hline $\begin{array}{l}\text { (6aR_1laR)-9_10-Dimethoxypterocarpan- } \\
\text { 3-O-beta-D-glucoside }\end{array}$ & Angelica sinensis (Oliv.) Diels & 106.26 & 105.61 & 93.609 \\
\hline Bixin & Desmodium gangeticum (L.) DC. & 59.09 & 53.08 & 92.671 \\
\hline 5CP_A_600* & & 78.02 & 68.27 & 25.155 \\
\hline
\end{tabular}

${ }^{*}$ Control.

will cause anhedonia. Therefore, MDD could be susceptible to treatment by $\beta$-CaMKII inhibition.

Computer-aided drug design (CADD) is a rapid and low-cost in silico simulation technique to screen for novel drug-candidate compounds by structure and prediction of biological activity. CADD has two major application areas, those of structure-based drug design and ligand-based drug design. The structure-based drug design system contains molecular docking and molecular dynamics simulation [49]. These techniques can help in the analysis of protein-ligand interactions by structure variation.

An understanding of personalized medicine and biomedicine, such as the analysis of regional diseases [10], clinical diagnosis cases, and disease associated mutations [11], has recently been attracting more and more attention [12]. Traditional Chinese medicine (TCM) is defined as a personalized medicine that has long been popular in Asia and has an important role in Asian culture. The largest traditional Chinese medicine database in the world, the TCM Database@Taiwan (http://tcm.cmu.edu.tw/) [13], has been established. In this database, 2D chemical structure, 3D chemical structure, and the bioactivity of 61,000 compounds extracted from TCM herbs can be searched. Since 2011, the TCM Database@Taiwan has been investigated for treatments for insomnia [14], pigmentary disorders [15], Parkinson's disease prevention [16], EGFR inhibition [17], pain relief [5], 
<smiles>CNc1cc(Nc2cc(C3CC3)n[nH]2)nc(Nc2ccc(CC#N)cc2)n1</smiles>

(a)<smiles>C=C(CC)[C@H]1C(=C)CC[C@H]2[C@@H](CN[C@@H](CC(N)=O)C(=O)O)C(=O)O[C@H]12</smiles>

(b)<smiles>O=C(/C=C\c1ccc(O)c(O)c1)Oc1ccc(C[C@H](O)C(=O)O)cc1O</smiles>

(c)<smiles>COc1cc(/C=C/C(=O)O[C@@H]2C[C@](C)(C(=O)O)C[C@H](O)[C@H]2O)ccc1O</smiles>

(d)

FIGURE 2: The 2D structure of the control and candidate TCM compounds. (a) 5CP, (b) sengesterone, (c) labiatic acid, and (d) methyl 3-Oferuloylquinate.

and antivirals [18-22]. The TCM Database@Taiwan can help users to screen TCM compounds via a cloud computing platform $[23,24]$.

In this research, we look for TCM compounds to inhibit $\beta$-CaMKII by analyzing their interactions. Candidate compounds are selected according to the docking and structure variations which outperform a control.

\section{Materials and Methods}

2.1. Data Set. The Accelrys Discovery Studio 2.5 (DS 2.5) was the platform used for molecule simulation. The TCM compounds were downloaded from TCM database (http:// tcm.cmu.edu.tw/). The $\beta$-CaMKII (PDB ID: $3 \mathrm{BHH}$ ) crystal structure and the control (4-((4-)(5-cyclopropyl-1H-pyrazol3-yl)amino)-6-(methylamino)pyrimidin-2-yl)amino)phenyl) acetonitrile (also called 5CP and DB07168) were downloaded from the PDB database [25]. The ID of 5CP in PubChem is CID 23624249, and this drug has been defined as a ligand for human calcium/calmodulin-dependent protein kinase IIB isoform 1 (camk2b).

2.2. Disorder Protein Detection. Protein disorder will define the difficulty with which a drug affects a protein. For this reason, the protein sequence should be submitted to the database of protein disorder (DisProt, http://www.disprot.org/) for disorder prediction [26].

The important amino acids are defined as Gly21, Val28, Ala41, Lys43, Val74, Phe90, Gly95, Gly96, Gln97, Asn141, Leu143, Asp157, and Phe158 which can interact with 5CP (defined by Lichtarge lab 2006). The disorder prediction can identify the protein character of the docking site, allowing the conditions of the protein-ligand interaction to be discussed.

2.3. Molecular Docking. LigandFit [27] is a receptor-rigid docking algorithm program in Discovery Studio 2.5 (DS 2.5) under the force field of CHARMm [28]. The docking site was established as the $5 \mathrm{CP}$ docking site, which is near to 


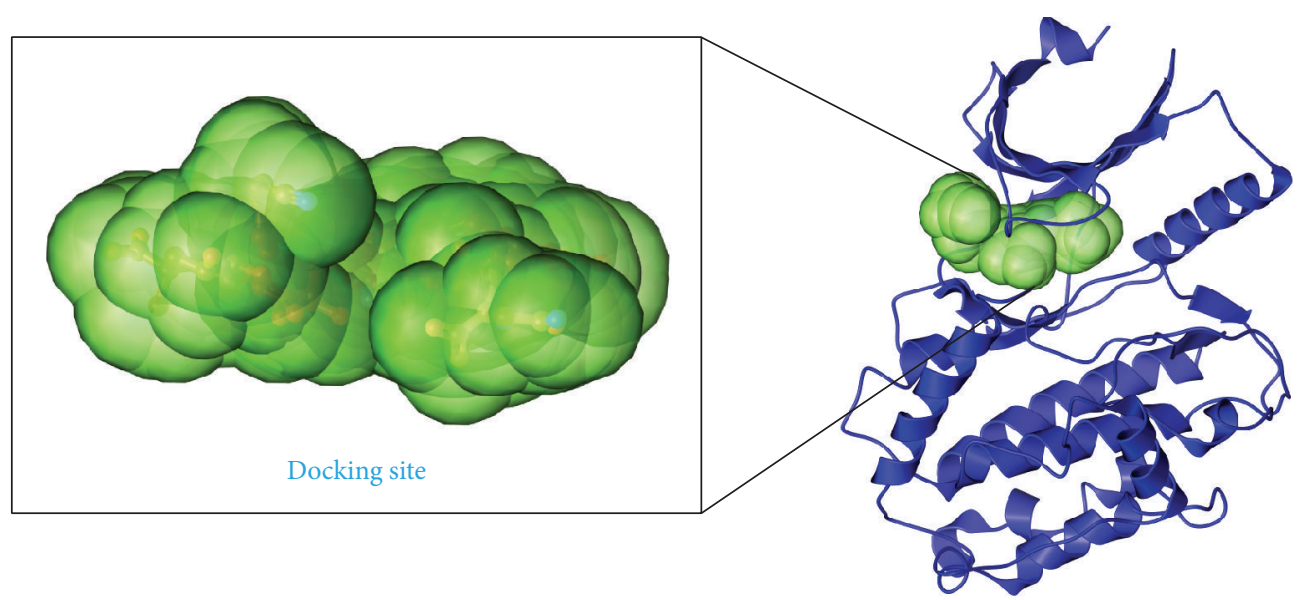

(a)

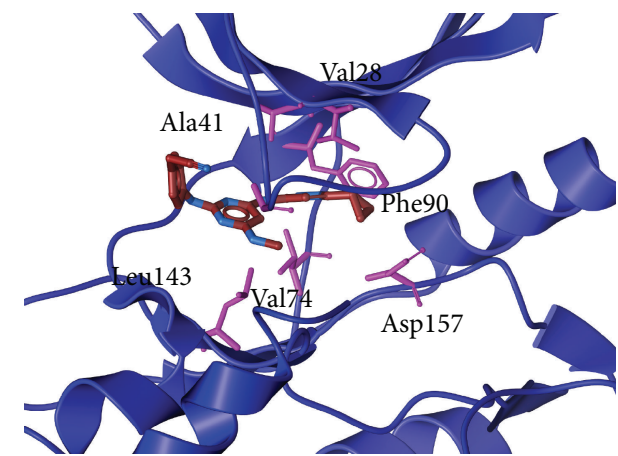

(b)

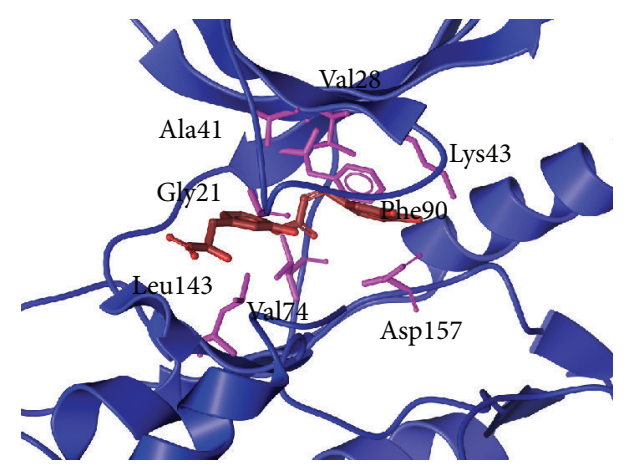

(d)

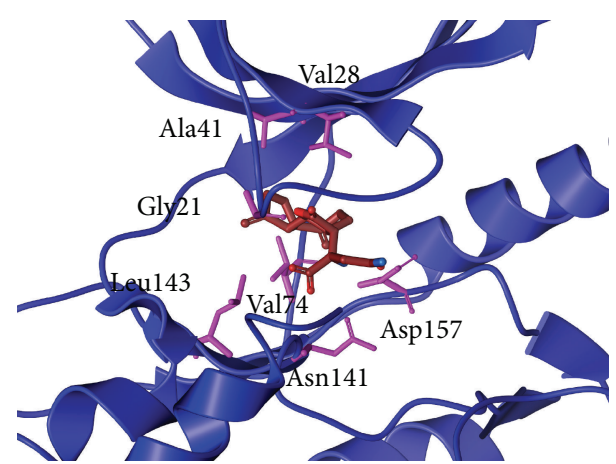

(c)

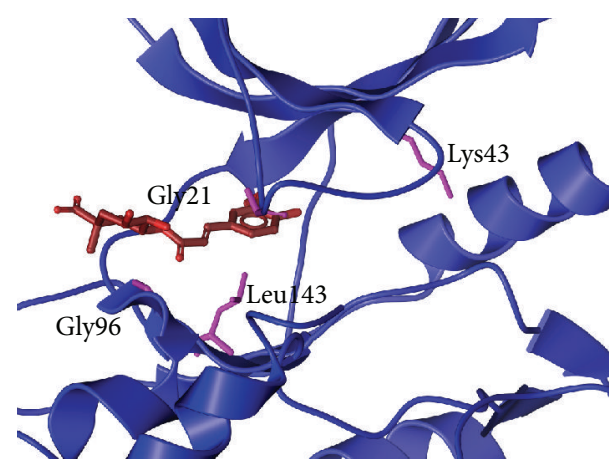

(e)

FIGURE 3: The docking poses of the ligands. (a) The crystal structure of $\beta$-CaMKII and the docking site, (b) 5CP, (c) sengesterone, (d) labiatic acid, and (e) methyl 3-O-feruloylquinate.

important amino acids. Ligplot analyzes the hydrophobic interactions for the selected compounds after docking [29, 30].

2.4. Molecular Dynamics Simulation. These ligands must be prepared by using SwissParam (http://swissparam.ch/) [31] on the force field [32] of GROMACS 4.5.5 [33]. After ligand preparation, the complex of $\beta$-CaMKII and ligands are transferred to the buffer (or solution) simulation box. The distance between the complex and the box is a minimum distance of $1.2 \AA$. This cubic box is a TIP3P water-solution model containing sodium and chloride ions to neutralize complex charges. The minimization used the steepest descent method for 5,000 steps before transferring the final structure to MD simulation. The electrostatic interactions were on the basis of the particle-mesh Ewald (PME) method with $2 \mathrm{fs}$ per time step for a total of 10,000,000 iterations for calculations [34]. The equilibration was based on the Berendsen weak thermal coupling method under a 100 ps constant temperature (NVT ensemble). After $20 \mathrm{~ns}$ of simulation, the MD trajectories, RMSD, and energy variations of the complex were analyzed using a series of the protocols in Gromacs. 


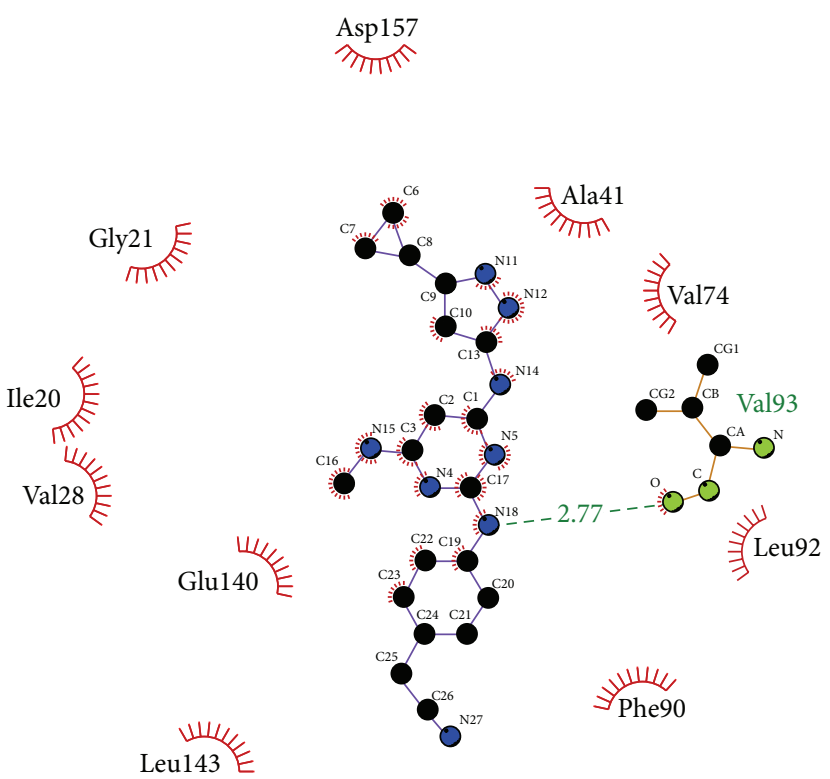

(a)

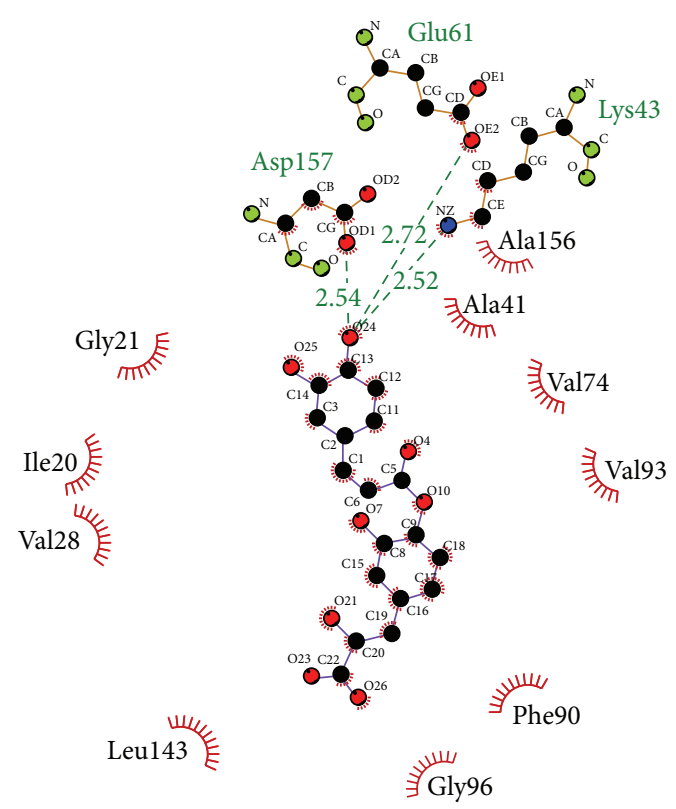

(c)

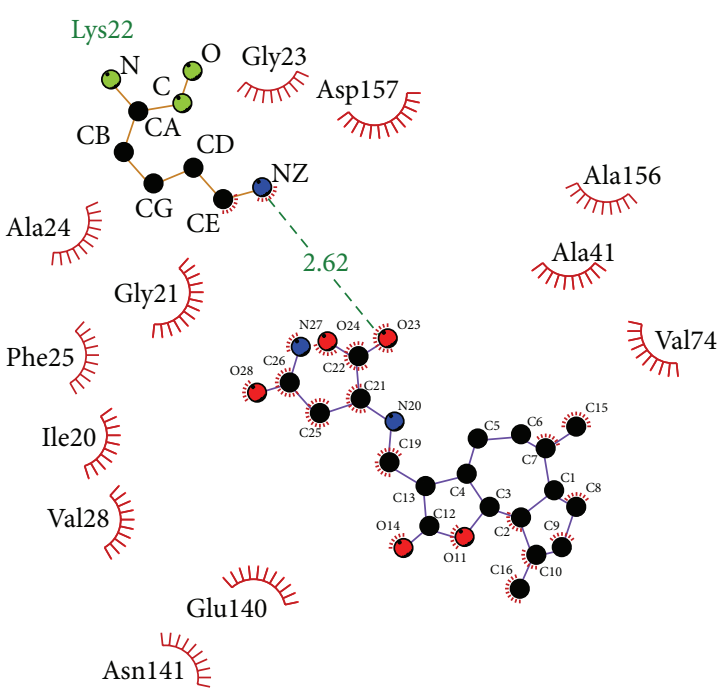

Leu143 崖

(b)

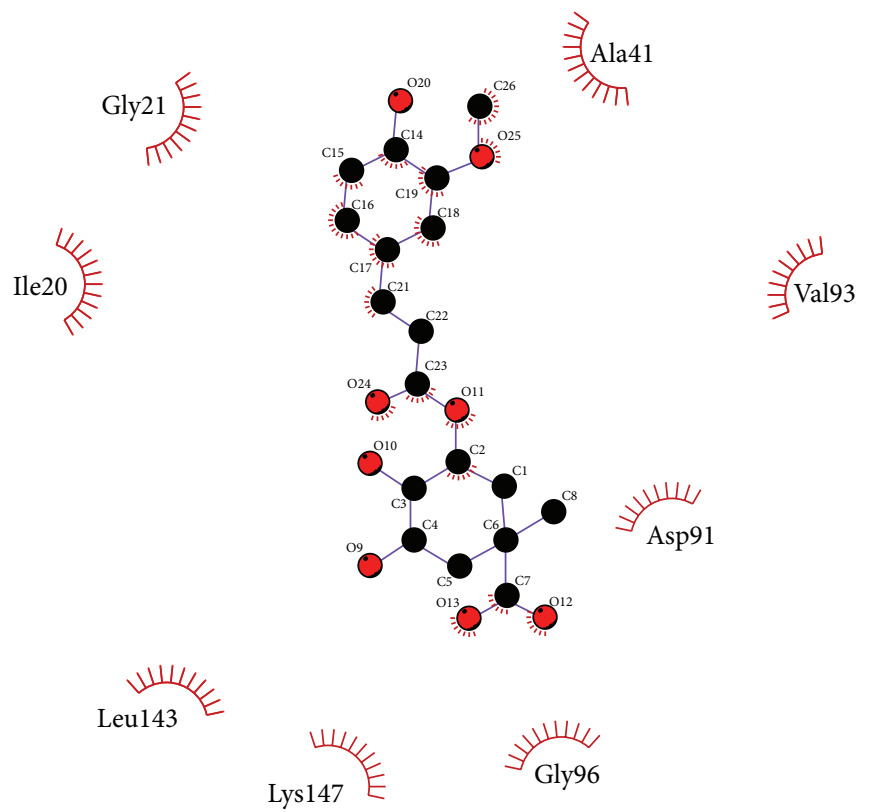

(d)

FIGURE 4: Ligplot illustrates the hydrophobic interactions. (a) 5CP, (b) sengesterone, (c) labiatic acid, and (d) methyl 3-O-feruloylquinate. The deep red color of the hydrophobic interactions indicates a high frequency in all ligand interactions.

\section{Results and Discussion}

3.1. The Detection of Disorder Protein. Protein disorder refers to an unstructured protein, and such characters for the docking site will make drug docking to the protein challenging and thus the complex will not be able to stabilize easily. Recent references $[7,35]$ indicate that protein disorder is not a common domain; thus, the drug will not dock to similar domains and become responsible for developing side effects. For the above reason, disorder for drug design is not a bad situation and should be defined as difficult work only. The important amino acids of $\beta$-CaMKII, Gly21, Val28, Ala41, Lys43, Val74, Phe90, Gly95, Gly96, Gln97, Asn141, Leu143, Asp157, and Phe158, are defined as nondisorder regions (Figure 1). For the discussion about the disordered region, the complex with $\beta$-CaMKII and compounds may be stable.

3.2. Molecular Docking. The top three TCM compounds from the database were selected as candidate compounds 

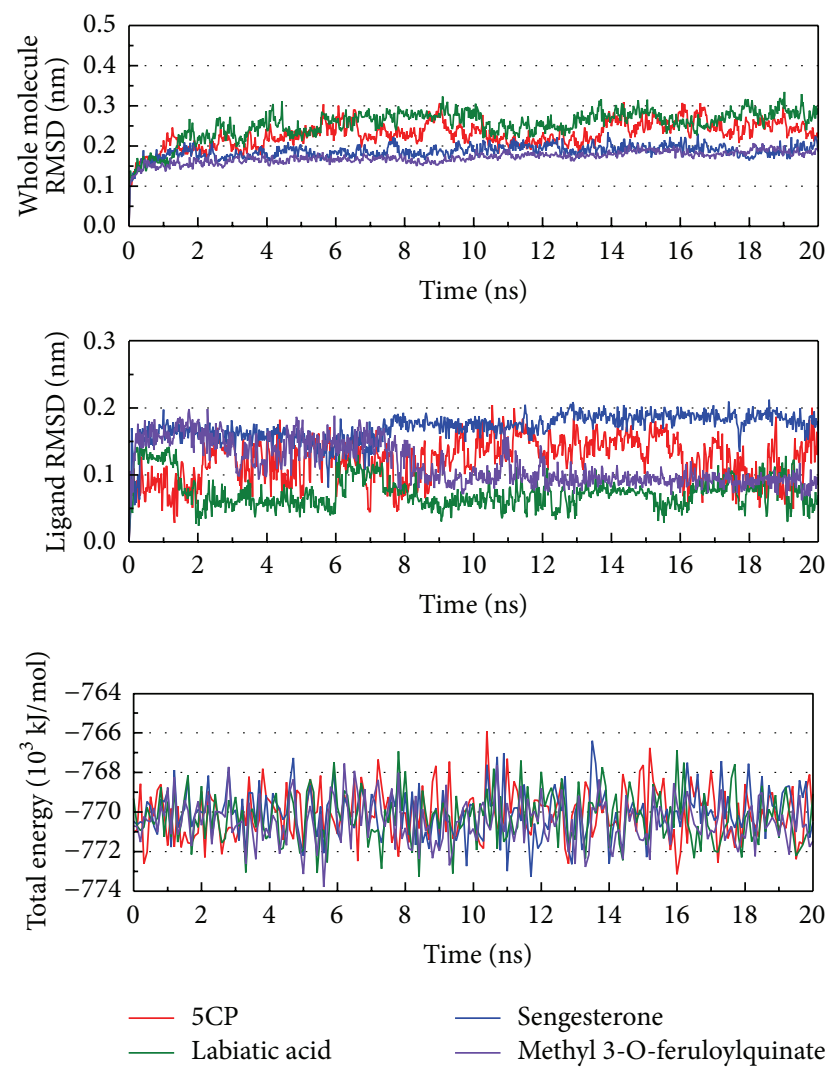

Figure 5: Measures of the MD trajectories. (a) Complex RMSD, (b) ligand RMSD, and (c) the total energy.

for molecular dynamics, according to the ranked docking score (Table 1). These compounds were in order sengesterone, extracted from Cyathula capitata Moq., labiatic acid, extracted from Rosmarinus officinalis L., and methyl 3-Oferuloylquinate, extracted from Phellodendron chinense C. K. Schneid. (Figure 2). Sengesterone, from the herb Cyathula capitata, has been shown to be an insect metamorphosing substance [36]. Labiatic acid from the herb Rosmarinus officinalis L. is analgesic and anti-inflammatory [37], has hypoglycemic and hepatoprotective activity [38], regulates glucose and lipid metabolism [39], attenuates oxidative stress, reduces blood cholesterol concentrations [40], improves memory impairment, and affects acetylcholinesterase and butyrylcholinesterase activities [41]. Methyl 3-O-feruloylquinate is an antiviral that has been used in the treatment of H5N1 [42] and, from Phellodendron amurense Rupr., can regulate fatty acids [43], protect human osteoarthritic cartilage [44], treat Alzheimer's disease [45], and have an anti-inflammatory [46], an antimicrobial, and anti-herpes simplex virus type 1 activity [47]. This compound has also been found to suppress the cellular immune response $[48,49]$. The compounds other than the top compound have been found to regulate memory and emotion [41, 45].

The docking poses are presented in Figure 3, and these results show the ligand interaction with the important amino acids of $\beta$-CaMKII. From this result, it can be seen that similar amino acids indicate that the ligand may have the same effect while docking.
The hydrophobic interaction is calculated by Ligplot (Figure 4). The important amino acids Gly21, Val28, Ala41, Lys43, Val74, Phe90, Gly96, Gln97, Leu143, and Asp157 have a high frequency in the result. This indicates that the defined simulation could present the real protein-ligand binding situation.

3.3. Molecular Dynamics Simulation. The variation of complex RMSD, ligand RMSD, and total energy can help analyze the situation during MD (Figure 5). In Figure 5, the RMSD of the complex and ligand are around, or lower than, $0.2 \mathrm{~nm}$. This result indicates that the protein, ligand, and their complex are stable and that their position and structure variation are not too large. In this ligand, RMSD has a large variation; however, labiatic acid and the complex RMSD of labiatic acid and methyl 3-O-feruloylquinate have a small variation, suggesting that the effect of labiatic acid is moderate. The total energy tends to the range between -772000 and $-778000 \mathrm{~kJ} / \mathrm{mol}$. From these results, we suggest this simulation will balance quickly according to the stable character of the protein.

Next, we discuss the hydrogen bond variation between protein-control interaction and protein-compounds interaction (Figures 6, 7, 8, and 9). In Figure 6(a), we selected the protein atom with $\mathrm{H}$-bond (defined by the distance $<0.3 \mathrm{~nm}$ ) occupancy greater than $20 \%$ to define the interaction and then we compared the different interactions between MD 0 ns and MD 20 ns in Figure 6(b). In this result, it can be found 


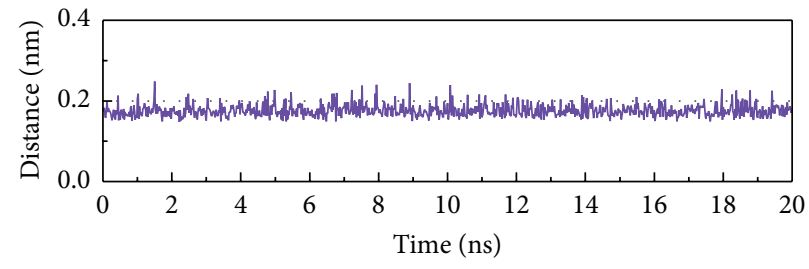

— ASP91:O/H35

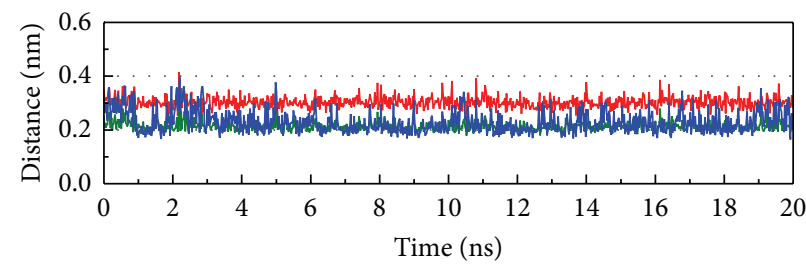

_ VAL93:HN/N11

— VAL93:HN/N12

— VAL93:O/H36

(a)
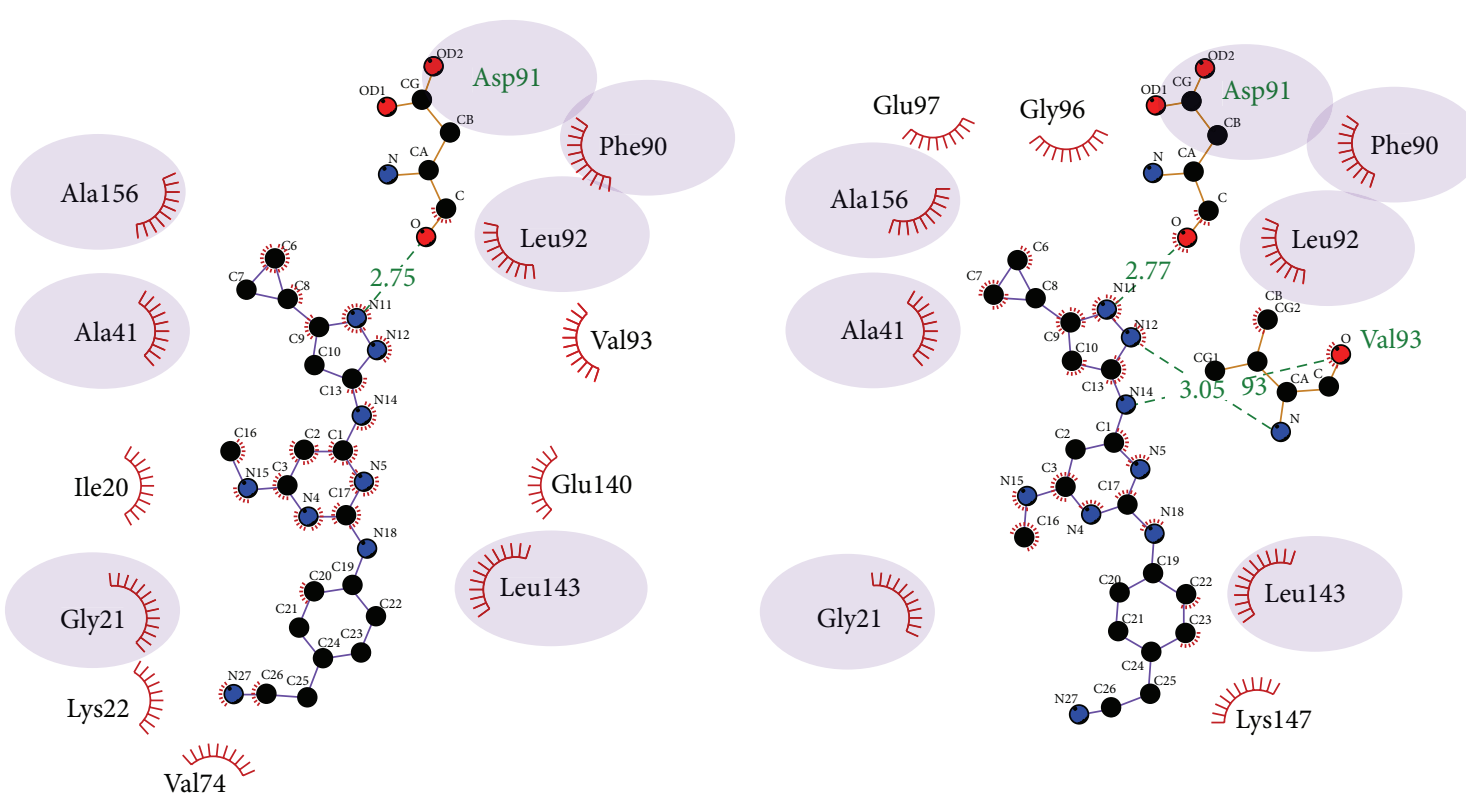

(b)

Figure 6: The interaction of 5CP and $\beta$-CaMKII complex in MD simulation. (a) H-bond variation and (b) hydrophobic variation.

that Asp91 has an important role in CAMKII, as this amino acid maintains the $\mathrm{H}$-bond throughout the MD simulation. Val93 also has high occupancy and has many simultaneous $\mathrm{H}$-bonds from different atoms. As Val93 does not produce $\mathrm{H}$-bonds at the beginning of the MD simulation, we suggest that Val 93 has a greater effect on interactions than the ligand target.

Based on the above description, Asp157 is important in the interaction from the start of the MD simulation as the distance becomes shorter and $\mathrm{H}$-bonds are produced with the principle compound, as seen in Figure 7. After the analysis of the interaction data from the second and third compounds chosen, we could not find one H-bond occupancy over $50 \%$.
When we censored the H-bond interactions, we found that these amino acids were all in the domain which influences protein kinase, especially in the region 20-28, which is the ATP and nucleotide binding site. The difference from the control is that the TCM compounds interact with amino acids and become $\mathrm{H}$-bonded in sequences $20-28$ and 147-157, but not in sequences 90-98. We suggest the regions other than region 20-28 may be important in $\beta$-CaMKII.

Finally, we discuss the interaction based on structure variation and ligand pathways in proteins (Figures 10-13). The pathway definition is based on the calculation of caver 3.0 to determine the interpath protein path during MD simulation [50]. 

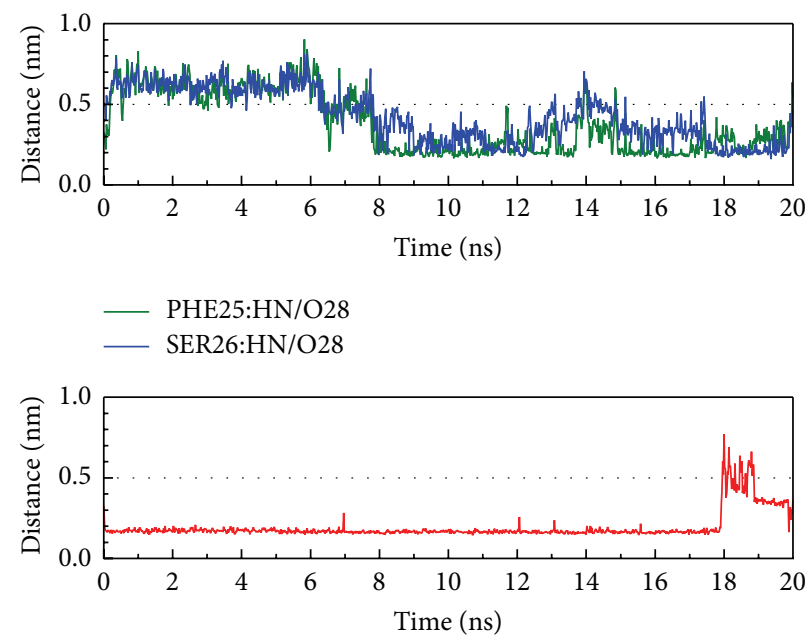

— ASP157:OD2/H52

(a)
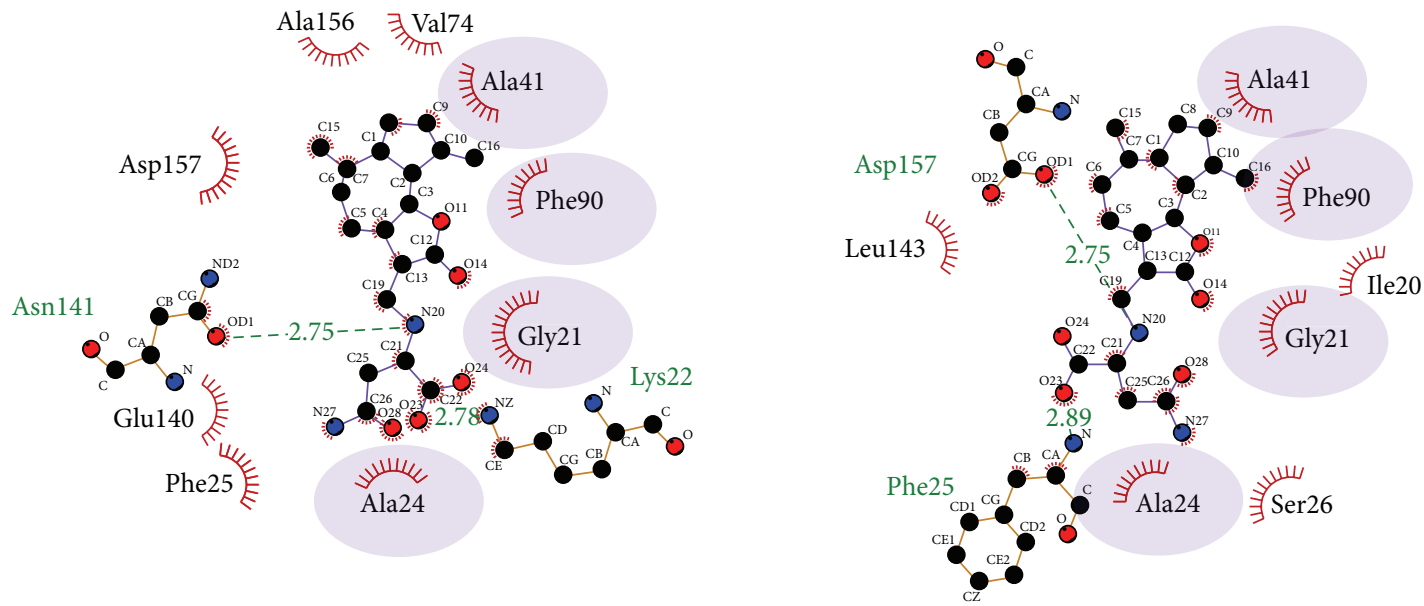

(b)

FIgURE 7: The interaction of sengesterone and $\beta$-CaMKII complex in MD simulation. (a) H-bond variation and (b) hydrophobic variation.

In Figure 10(a), there are three large protein variation sites while the ligand moves away during MD simulation. We suggest this variation makes the pore smaller so that no other ligand can have an effect on the domain. The result in Figure 10(b) shows the top four length pathways for 5CP. But, in these pathways, the third is in the protein structure and not in the docking site. In actuality, the ligand could not move through the protein structure even if the path range could allow the ligand to pass. Although there are still three possible pathways, Figure 10(a) shows the ligand moving away from the protein. Thus, ligand 1 or 2 may be the pathway for $5 \mathrm{CP}$. The difference from the control is that sengesterone, as the ligand target, moves inside the protein structure after MD simulation. In Figure 11(a), the structure variations of 1 and 2 are similar, but variation 3 is the opposite. We suggest this interaction causes the pore of the protein to change and thus inhibits the protein function. Consequently, the fifth pathway may be a possible pathway for sengesterone (Figure 11(b)).
Based on the larger variation of protein structure, we suggest labiatic acid may have a stronger effect on $\beta$-CaMKII (Figure 12(a)). The possible pathway will be different for these interactions. After the calculation, the results indicate that these pathways move to similar positions until they project out of the pore (Figure 12(b)). This phenomenon indicates that labiatic acid not only determines the protein and pore variation, but also prevents interactions with other ligands.

Methyl 3-O-feruloylquinate causes variation in $\beta$ CaMKII by interacting closely with the amino acids and then the pore (Figure 13(a)). Although this pathway was predicted, we suggest, based on a 20 ns simulation, that this compound will occupy a position that will prevent other interactions and inhibit the protein function.

The results of structure variation indicate these compounds could cause protein variations that would result in inhibition of the protein function. 


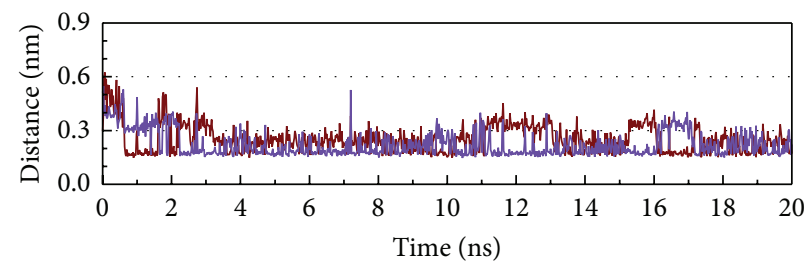

- ASP157:OD1/H40

- ASP157:OD2/H40

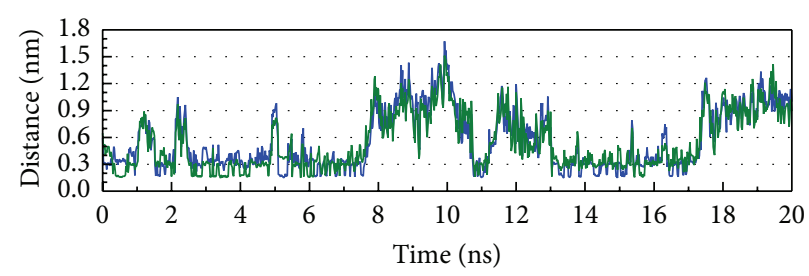

— LYS22:HZ3/O23

— LYS22:HZ3/O26

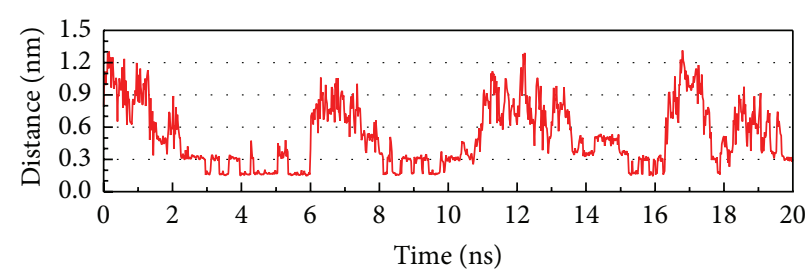

_ L LYS147:HZ3/O23

(a)
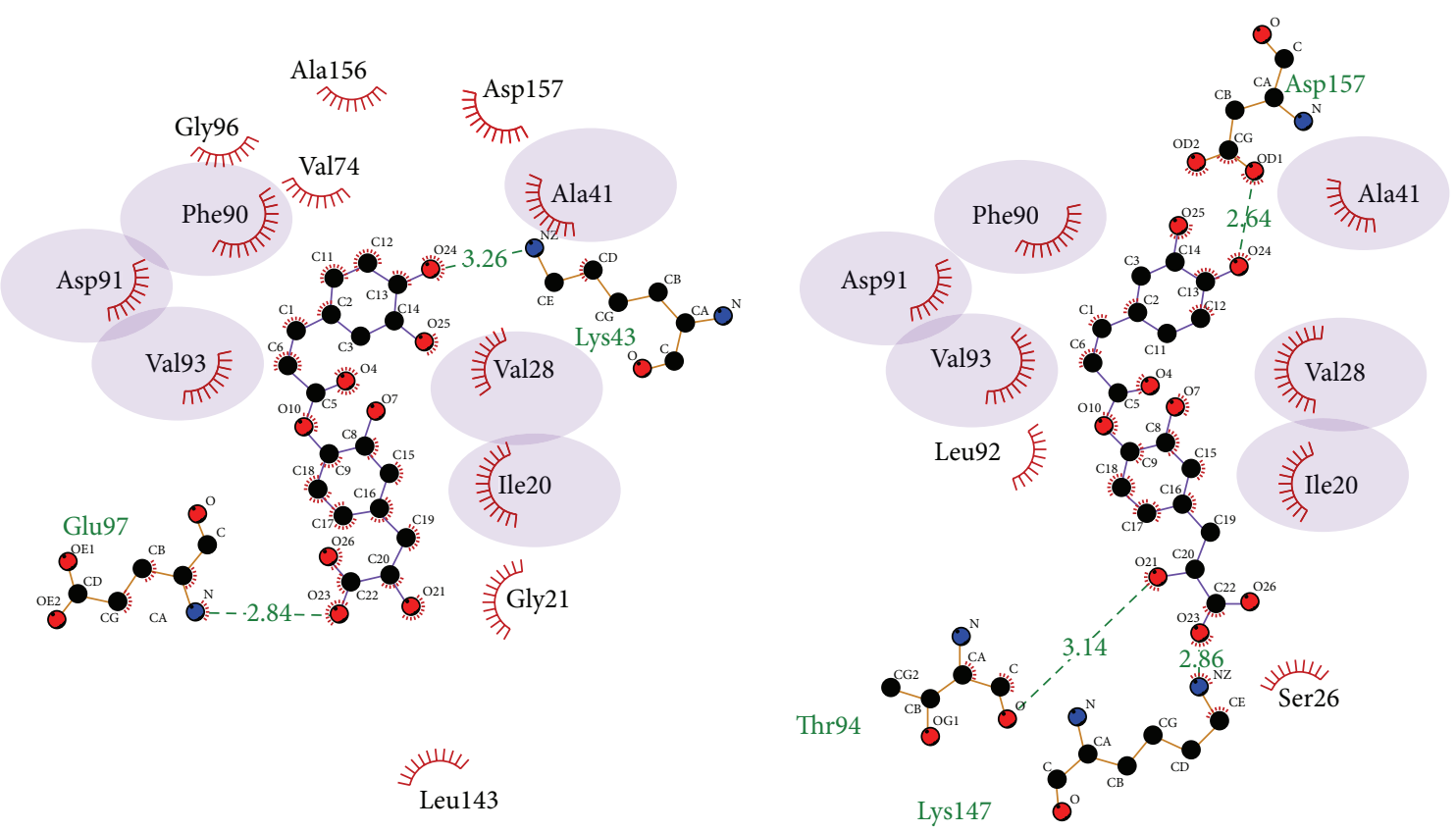

(b)

FIGURE 8: The interaction of labiatic acid and $\beta$-CaMKII complex in MD simulation. (a) H-bond variation and (b) hydrophobic variation. 


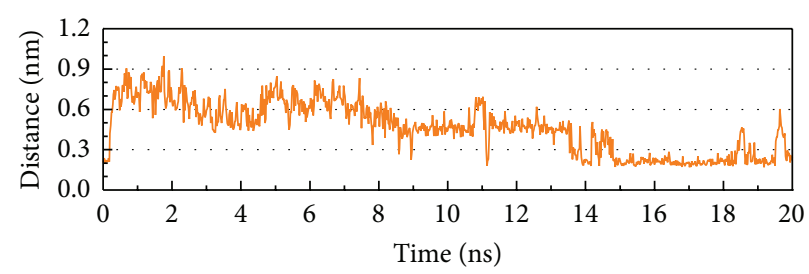

— GLY21:HN/O10

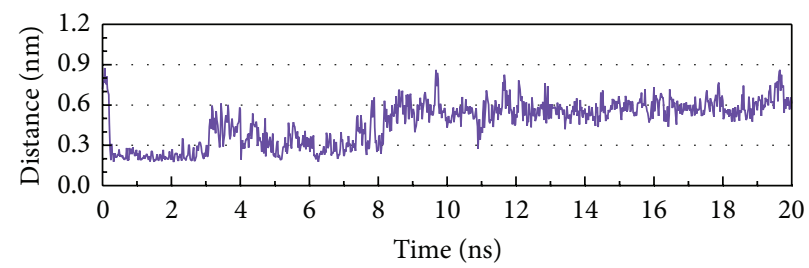

- GLU97:HN/O10

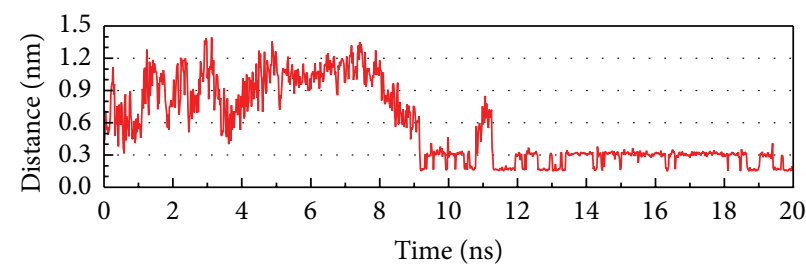

_ LYS147:HZ3/O13

(a)
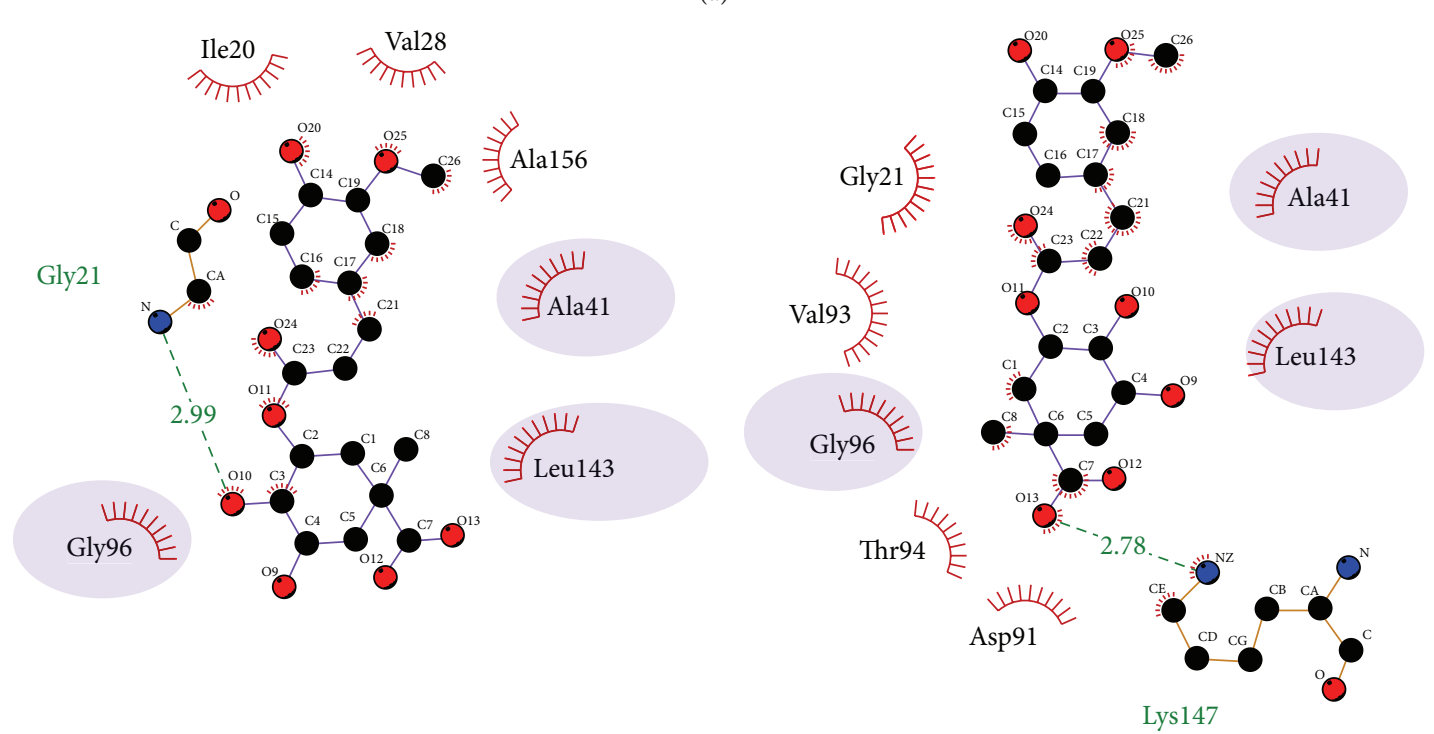

(b)

FIGURE 9: The interaction of methyl 3-O-feruloylquinate and $\beta$-CaMKII complex in MD simulation. (a) H-bond variation and (b) hydrophobic variation.

\section{Conclusion}

In the analysis of docking, the docking site and the ligand dock to the protein are correct based on the important amino acid interactions. The RMSD and energy show that $\beta$-CaMKII is a stable protein, according to low variation in the interaction and sample functional structure of important amino acids. $\beta$-CaMKII can maintain the composition of its structure during these important amino acid interactions. From this situation, we find that some proteins may prevent the large variations necessary for some amino acids to compose the functional domain. Finally, we suggest that these compounds may be able to regulate emotion, and we think sengesterone may have stronger effect than the others. 


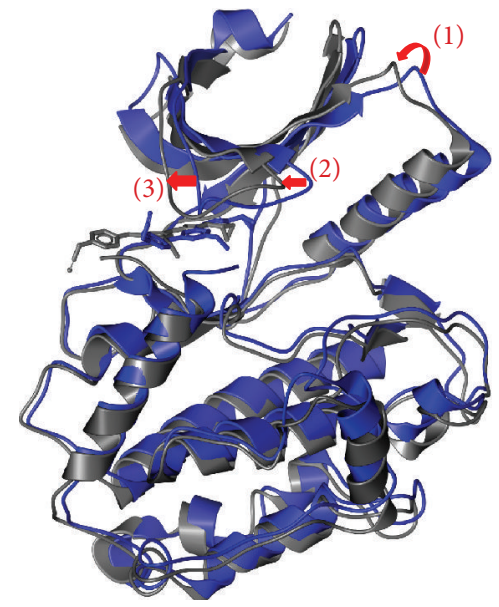

(a)
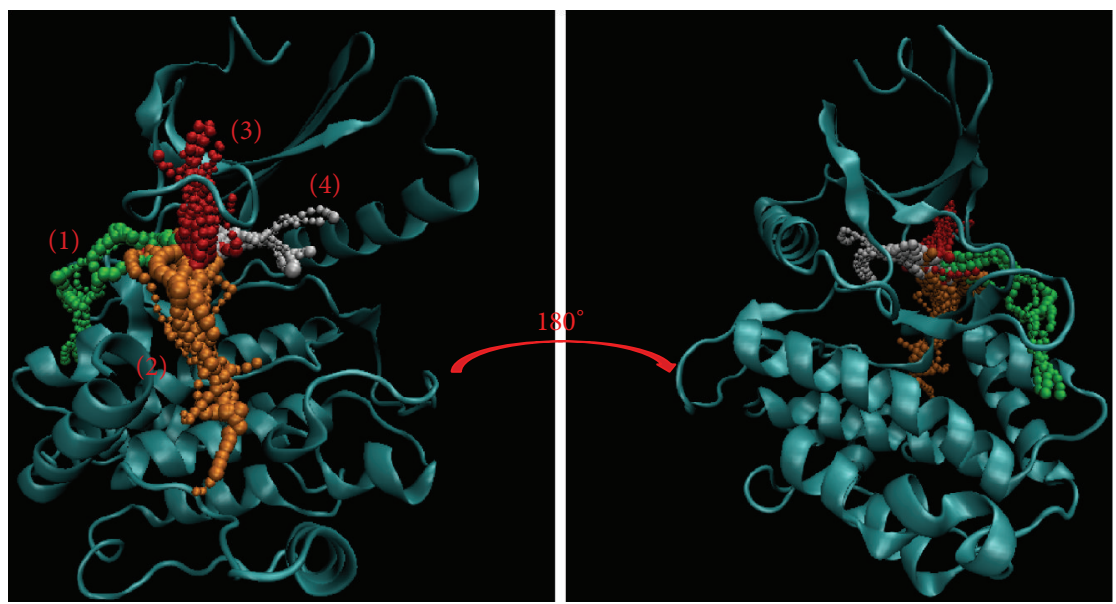

(b)

FIgURE 10: The variation of 5CP and $\beta$-CaMKII complex in MD simulation. (a) Structure variation and (b) pathway prediction.

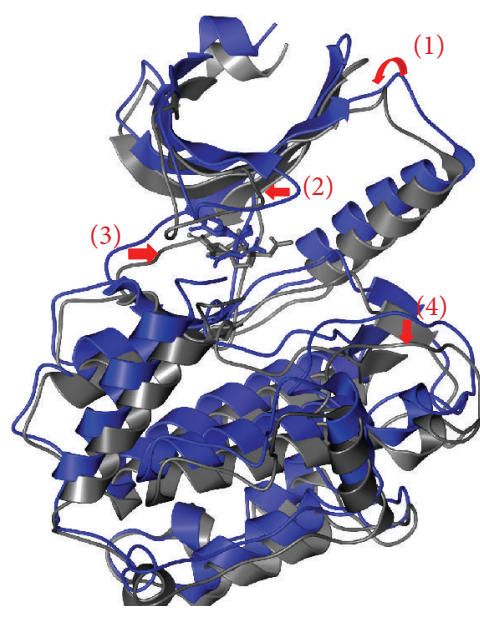

(a)
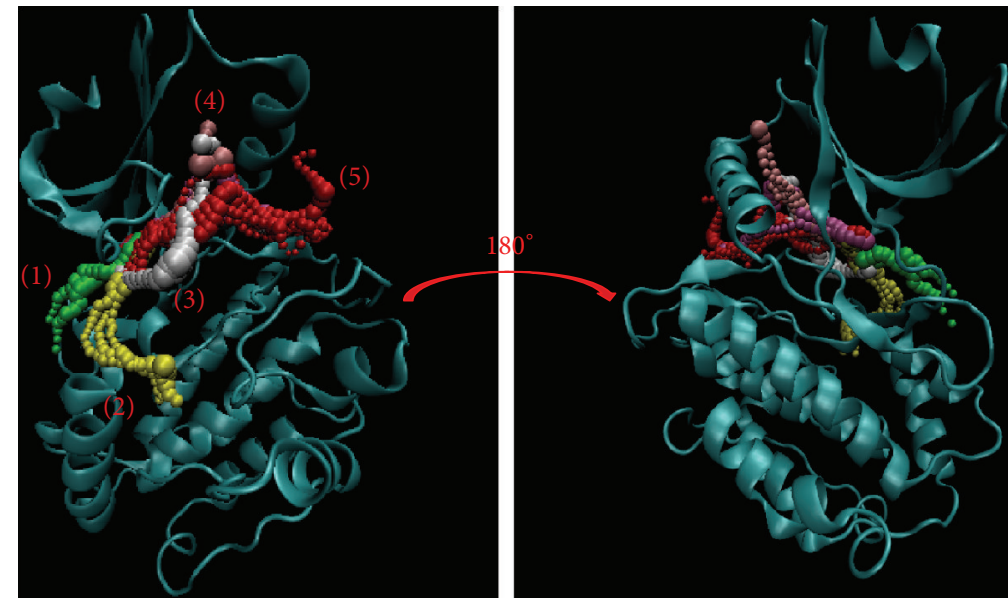

(b)

FIGURE 11: The variation of sengesterone and $\beta$-CaMKII complex in MD simulation. (a) Structure variation and (b) pathway prediction.

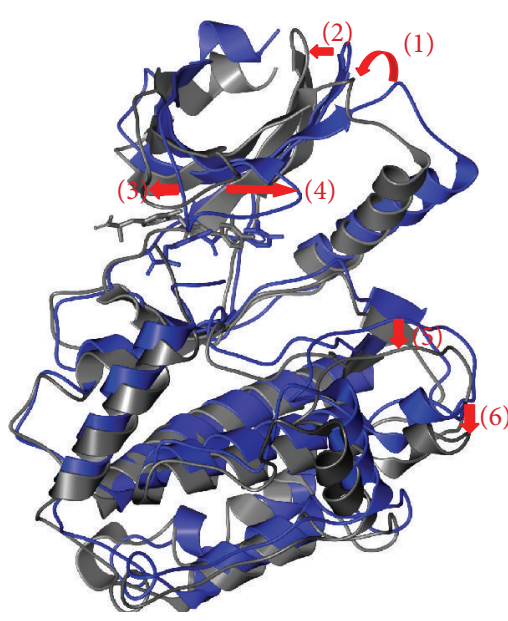

(a)
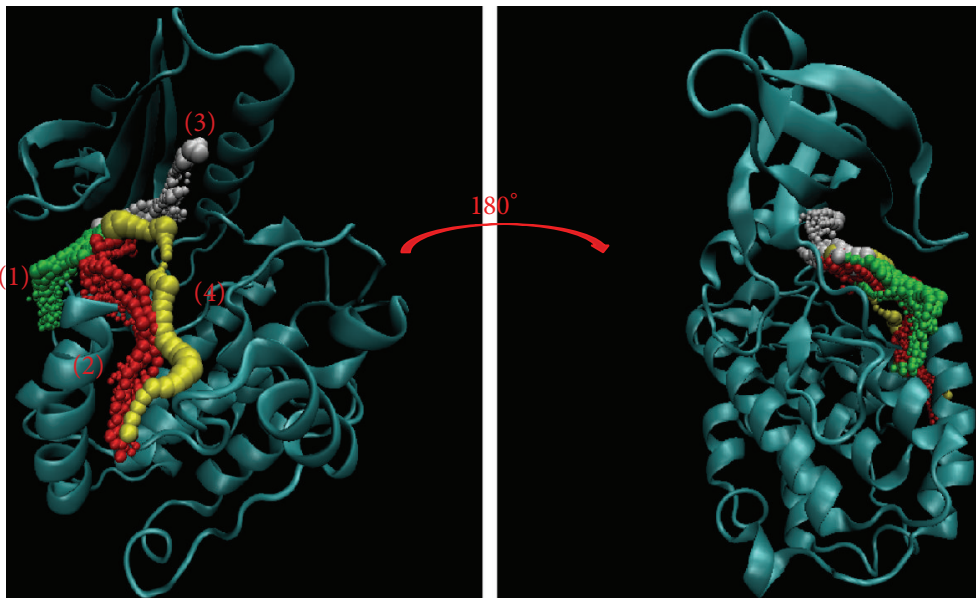

(b)

FIgURE 12: The variation of labiatic acid and $\beta$-CaMKII complex in MD simulation. (a) Structure variation and (b) pathway prediction. 


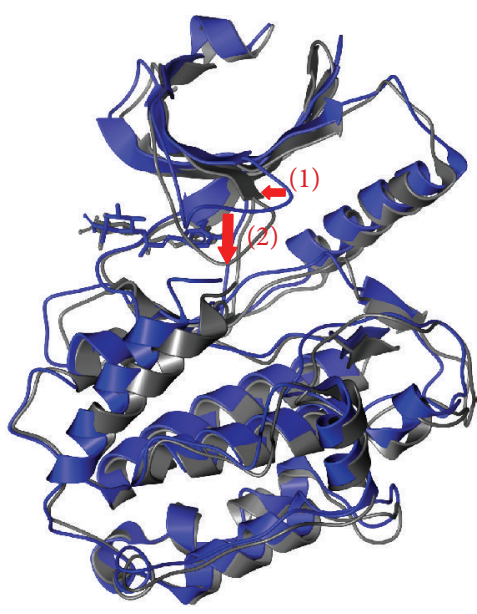

(a)
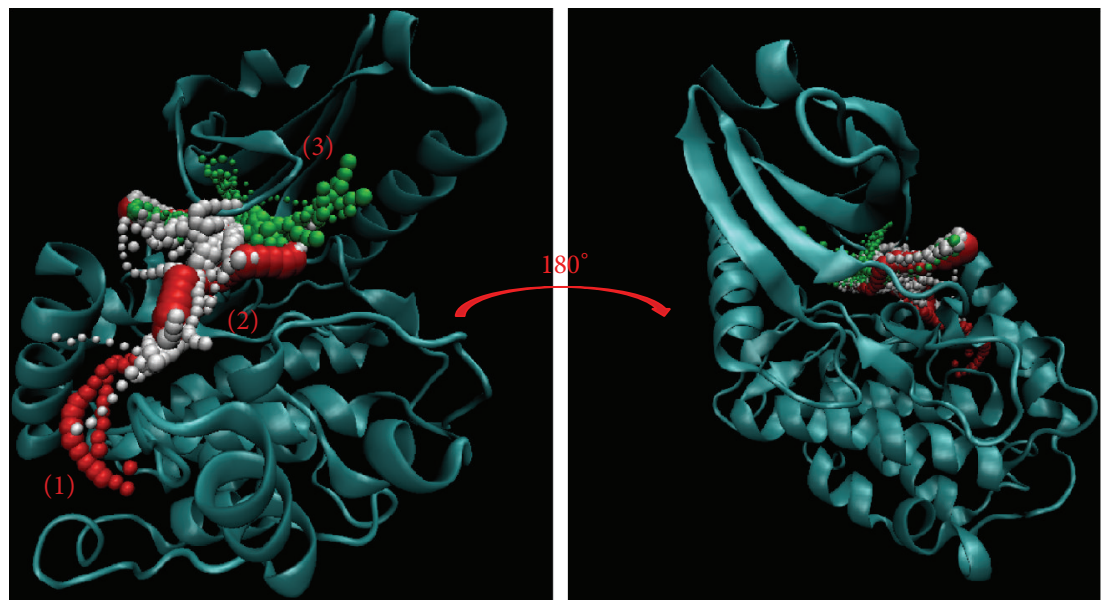

(b)

FIgURE 13: The variation of methyl 3-O-feruloylquinate and $\beta$-CaMKII complex in MD simulation. (a) Structure variation and (b) pathway prediction.

\section{Conflict of Interests}

The authors declare that there is no conflict of interests.

\section{Authors' Contribution}

Tzu-Chieh Hung, Wen-Yuan Lee, Kuen-Bao Chen, and Hung-Jin Huang contributed equally to this work.

\section{Acknowledgments}

The research was supported by Grants from the National Science Council of Taiwan (NSC102-2325-B039-001, NSC1022221-E-468-027-), Asia University (ASIA100-CMU-2, ASIA101-CMU-2, and 102-Asia-07), and China Medical University Hospital (DMR-103-058, DMR-103-001, and DMR103-096). This study is also supported in part by Taiwan Department of Health Clinical Trial and Research Center of Excellence (DOH102-TD-B-111-004), Taiwan Department of Health Cancer Research Center of Excellence (MOHW103TD-B-111-03), and CMU under the Aim for Top University Plan of the Ministry of Education, Taiwan. The authors also thank Yi-Teh Liu for helping in the analysis of these data. Finally, our gratitude goes to Dr. Tim Williams, Asia University.

\section{References}

[1] G. Novak, P. Seeman, and T. Tallerico, "Increased expression of calcium/calmodulin-dependent protein kinase II $\beta$ in frontal cortex in schizophrenia and depression," Synapse, vol. 59, no. 1, pp. 61-68, 2006.

[2] T. Suenaga, S. Morinobu, K.-I. Kawano, T. Sawada, and S. Yamawaki, "Influence of immobilization stress on the levels of CaMKII and phospho-CaMKII in the rat hippocampus," International Journal of Neuropsychopharmacology, vol. 7, no. 3, pp. 299-309, 2004.
[3] K. Li, T. Zhou, L. Liao et al., " $\beta$ CaMKII in lateral habenula mediates core symptoms of depression," Science, vol. 341, no. 6149, pp. 1016-1020, 2013.

[4] H.-J. Huang, H. W. Yu, C.-Y. Chen et al., "Current developments of computer-aided drug design," Journal of the Taiwan Institute of Chemical Engineers, vol. 41, no. 6, pp. 623-635, 2010.

[5] W. I. Tou, S.-S. Chang, C.-C. Lee, and C. Y.-C. Chen, "Drug design for neuropathic pain regulation from traditional Chinese medicine," Scientific Reports, vol. 3, article 844, 2013.

[6] C. Y.-C. Chen, "A novel integrated framework and improved methodology of computer-aided drug design," Current Topics in Medicinal Chemistry, vol. 13, no. 9, pp. 965-988, 2013.

[7] C. Y.-C. Chen and W. I. Tou, "How to design a drug for the disordered proteins?" Drug Discovery Today, vol. 18, no. 19-20, pp. $910-915,2013$.

[8] S. C. Basak, "Recent developments and future directions at current computer aided drug design," Current Computer-Aided Drug Design, vol. 9, no. 1, article 1, 2013.

[9] C. Y.-C. Chen, "Weighted equation and rules-a novel concept for evaluating protein-ligand interaction," Journal of Biomolecular Structure and Dynamics, vol. 27, no. 3, pp. 271-282, 2009.

[10] C.-C. Lee, C.-H. Tsai, L. Wan et al., "Increased incidence of Parkinsonism among Chinese with $\beta$-glucosidase mutation in central Taiwan," BioMedicine, vol. 3, no. 2, pp. 92-94, 2013.

[11] I.-C. Chou, W.-D. Lin, C.-H. Wang et al., "Möbius syndrome in a male with XX/XY mosaicism," BioMedicine, vol. 3, no. 2, pp. 102-104, 2013.

[12] W.-L. Liao and F.-J. Tsai, "Personalized medicine: a paradigm shift in healthcare," BioMedicine, 2013.

[13] C. Y.-C. Chen, “TCM Database@Taiwan: the world's largest traditional Chinese medicine database for drug screening in silico," PLoS ONE, vol. 6, no. 1, Article ID e15939, 2011.

[14] H. Y. Chen, S. S. Chang, Y. C. Chan, and C. Y. Chen, "Discovery of novel insomnia leads from screening traditional Chinese medicine database," Journal of Biomolecular Structure \& Dynamics, vol. 32, no. 5, pp. 776-791, 2014.

[15] H.-C. Tang and C. Y.-C. Chen, "Investigation of the novel lead of melanocortin 1 receptor for pigmentary disorders," 
Evidence-Based Complementary and Alternative Medicine, vol. 2014, Article ID 254678, 13 pages, 2014.

[16] H.-J. Huang, C.-C. Lee, and C. Y.-C. Chen, "Pharmacological chaperone design for reducing risk factor of parkinson's disease from traditional chinese medicine," Evidence-Based Complementary and Alternative Medicine, vol. 2014, Article ID 830490, 12 pages, 2014.

[17] S.-C. Yang, S.-S. Chang, H.-Y. Chen, and C. Y.-C. Chen, "Identification of potent EGFR inhibitors from TCM Database@Taiwan,” PLoS Computational Biology, vol. 7, no. 10, Article ID e1002189, 2011.

[18] S.-S. Chang, H.-J. Huang, and C. Y.-C. Chen, "High performance screening, structural and molecular dynamics analysis to identify H1 inhibitors from TCM Database@Taiwan," Molecular BioSystems, vol. 7, no. 12, pp. 3366-3374, 2011.

[19] C.-H. Lin, T.-T. Chang, M.-F. Sun et al., "Potent inhibitor design against H1N1 swine influenza: structure-based and molecular dynamics analysis for M2 inhibitors from traditional Chinese medicine database," Journal of Biomolecular Structure and Dynamics, vol. 28, no. 4, pp. 471-482, 2011.

[20] S.-S. Chang, H.-J. Huang, and C. Y.-C. Chen, "Two birds with one stone? Possible dual-targeting H1N1 inhibitors from traditional Chinese medicine," PLoS Computational Biology, vol. 7, no. 12, Article ID e1002315, 2011.

[21] C.-Y. Chen, Y.-H. Chang, D.-T. Bau et al., "Ligand-based dual target drug design for H1N1: swine flu-a preliminary first study," Journal of Biomolecular Structure and Dynamics, vol. 27, no. 2, pp. 171-178, 2009.

[22] H. J. Huang, Y. R. Jian, and C. Y. Chen, "Traditional Chinese medicine application in HIV: an in silico study," Journal of Biomolecular Structure \& Dynamics, vol. 32, no. 1, pp. 1-12, 2014.

[23] T.-Y. Tsai, K.-W. Chang, and C. Y.-C. Chen, "IScreen: world's first cloud-computing web server for virtual screening and de novo drug design based on TCM database@Taiwan," Journal of Computer-Aided Molecular Design, vol. 25, no. 6, pp. 525-531, 2011.

[24] K.-W. Chang, T.-Y. Tsai, K.-C. Chen et al., "iSMART: an integrated cloud computing web server for traditional Chinese medicine for online virtual screening, de novo evolution and drug design," Journal of Biomolecular Structure and Dynamics, vol. 29, no. 1, pp. 243-250, 2011.

[25] H. M. Berman, J. Westbrook, Z. Feng et al., "The protein data bank," Nucleic Acids Research, vol. 28, no. 1, pp. 235-242, 2000.

[26] B. Xue, R. L. Dunbrack, R. W. Williams, A. K. Dunker, and V. N. Uversky, "PONDR-FIT: a meta-predictor of intrinsically disordered amino acids," Biochimica et Biophysica Acta-Proteins and Proteomics, vol. 1804, no. 4, pp. 996-1010, 2010.

[27] C. M. Venkatachalam, X. Jiang, T. Oldfield, and M. Waldman, "LigandFit: a novel method for the shape-directed rapid docking of ligands to protein active sites," Journal of Molecular Graphics and Modelling, vol. 21, no. 4, pp. 289-307, 2003.

[28] B. R. Brooks, C. L. Brooks III, A. D. Mackerell Jr. et al., "CHARMM: the biomolecular simulation program," Journal of Computational Chemistry, vol. 30, no. 10, pp. 1545-1614, 2009.

[29] R. A. Laskowski and M. B. Swindells, "LigPlot+: multiple ligandprotein interaction diagrams for drug discovery," Journal of Chemical Information and Modeling, vol. 51, no. 10, pp. 27782786, 2011.

[30] A. C. Wallace, R. A. Laskowski, and J. M. Thornton, "LIGPLOT: a program to generate schematic diagrams of protein-ligand interactions," Protein Engineering, vol. 8, no. 2, pp. 127-134, 1995.
[31] V. Zoete, M. A. Cuendet, A. Grosdidier, and O. Michielin, "SwissParam: a fast force field generation tool for small organic molecules," Journal of Computational Chemistry, vol. 32, no. 11, pp. 2359-2368, 2011.

[32] U. D. Priyakumar and A. D. MacKerell, "Comparison of the CHARMM27, AMBER4. 1 and BMS nucleic acid force fields via free energy calculations of base flipping," Abstracts of Papers of the American Chemical Society, vol. 230, pp. U1391-U1392, 2005.

[33] B. Hess, C. Kutzner, D. Van Der Spoel, and E. Lindahl, "GRGMACS 4: algorithms for highly efficient, load-balanced, and scalable molecular simulation," Journal of Chemical Theory and Computation, vol. 4, no. 3, pp. 435-447, 2008.

[34] T. A. Darden and L. G. Pedersen, "Molecular modeling: an experimental tool," Environmental Health Perspectives, vol. 101, no. 5, pp. 410-412, 1993.

[35] W. I. Tou and C. Y. Chen, "May disordered protein cause serious drug side effect?” Drug Discovery Today, vol. 19, no. 4, pp. 367$372,2014$.

[36] H. Hikino, K. Nomoto, and T. Takemoto, "Sengosterone, an insect metamorphosing substance from Cyathula capitata: structure," Tetrahedron, vol. 26, no. 3, pp. 887-898, 1970.

[37] R. Lucarini, W. A. Bernardes, D. S. Ferreira et al., "In vivo analgesic and anti-inflammatory activities of Rosmarinus officinalis aqueous extracts, rosmarinic acid and its acetyl ester derivative," Pharmaceutical Biology, vol. 51, no. 9, pp. 1087-1090, 2013.

[38] K. S. Ramadan, O. A. Khalil, E. N. Danial, H. S. Alnahdi, and N. O. Ayaz, "Hypoglycemic and hepatoprotective activity of Rosmarinus officinalis extract in diabetic rats," Journal of Physiology and Biochemistry, vol. 69, no. 4, pp. 779-783, 2013.

[39] Z. Tu, T. Moss-Pierce, P. Ford, and T. A. Jiang, "Rosemary (Rosmarinus officinalis L.) extract regulates glucose and lipid metabolism by activating AMPK and PPAR pathways in HepG2 cells," Journal of Agricultural and Food Chemistry, vol. 61, no. 11, pp. 2803-2810, 2013.

[40] M. S. Afonso, A. M. De O Silva, E. B. Carvalho et al., "Phenolic compounds from Rosemary (Rosmarinus officinalis L.) attenuate oxidative stress and reduce blood cholesterol concentrations in diet-induced hypercholesterolemic rats," Nutrition and Metabolism, vol. 10, no. 1, article 19, 2013.

[41] M. Ozarowski, P. L. Mikolajczak, A. Bogacz et al., "Rosmarinus officinalis L. leaf extract improves memory impairment and affects acetylcholinesterase and butyrylcholinesterase activities in rat brain," Fitoterapia, vol. 91, pp. 261-271, 2013.

[42] F. Ge, C. Ke, W. Tang et al., "Isolation of chlorogenic acids and their derivatives from Stemona japonica by preparative HPLC and evaluation of their anti-AIV (H5N1) activity in vitro," Phytochemical Analysis, vol. 18, no. 3, pp. 213-218, 2007.

[43] D. Steinmann, R. R. Baumgartner, E. H. Heiss et al., "Bioguided isolation of (9 Z)-Octadec-9-enoic acid from phellodendron amurense ruprand identification of fatty acids as PTP1B inhibitors," Planta Medica, vol. 78, no. 3, pp. 219-224, 2012.

[44] J.-H. Kim, J.-E. Huh, Y.-H. Baek, J.-D. Lee, D.-Y. Choi, and D.-S. Park, "Effect of Phellodendron amurense in protecting human osteoarthritic cartilage and chondrocytes," Journal of Ethnopharmacology, vol. 134, no. 2, pp. 234-242, 2011.

[45] Y.-F. Xian, Z.-X. Lin, S.-P. Ip, Z.-R. Su, J.-N. Chen, and X.-P. Lai, "Comparison the neuropreotective effect of Cortex Phellodendri chinensis and Cortex Phellodendri amurensis against betaamyloid-induced neurotoxicity in PC12 cells," Phytomedicine, vol. 20, no. 2, pp. 187-193, 2013.

[46] E.-K. Park, I. R. Hae, H.-S. Jung et al., "Antiinflammatory effects of a combined herbal preparation (RAH13) of Phellodendron 
amurense and Coptis chinensis in animal models of inflammation," Phytotherapy Research, vol. 21, no. 8, pp. 746-750, 2007.

[47] W. Wang, Y. Zu, Y. Fu et al., "In vitro antioxidant, antimicrobial and anti-herpes simplex virus type 1 activity of Phellodendron amurense Rupr. from China," The American Journal of Chinese Medicine, vol. 37, no. 1, pp. 195-203, 2009.

[48] H. Mori, M. Fuchigami, N. Inoue et al., "Principle of the bark of Phellodendron amurense to suppress the cellular immune response: effect of Phellodendrine on cellular and humoral immune responses," Planta Medica, vol. 61, no. 1, pp. 45-49, 1995.

[49] H. Mori, M. Fuchigami, N. Inoue, H. Nagai, A. Koda, and I. Nishioka, "Principle of the bark of Phellodendron amurense to suppress the cellular immune response," Planta Medica, vol. 60, no. 5, pp. 445-449, 1994.

[50] E. Chovancova, A. Pavelka, P. Benes et al., "CAVER 3.0: a tool for the analysis of transport pathways in dynamic protein structures," PLoS Computational Biology, vol. 8, no. 10, Article ID e1002708, 2012. 

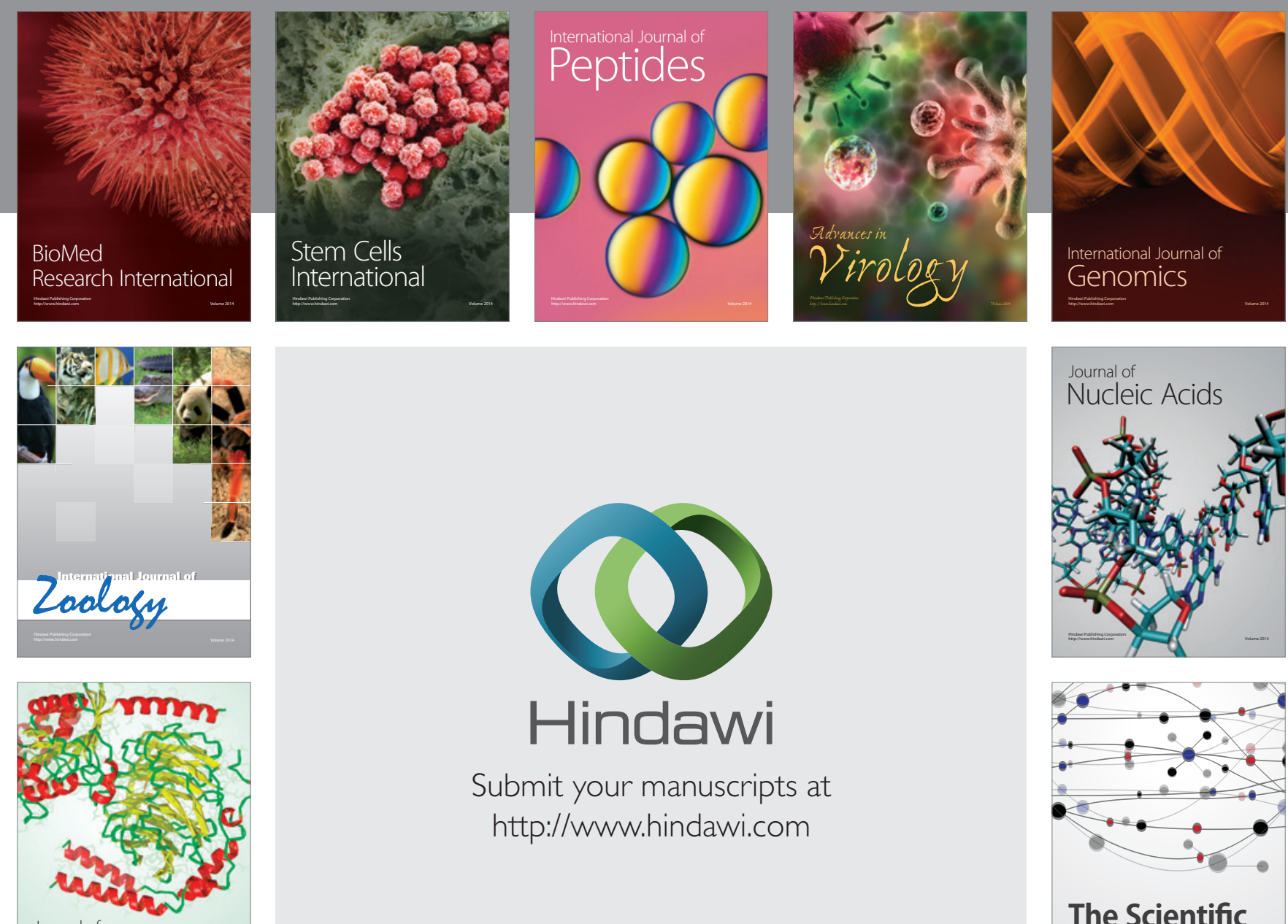

Submit your manuscripts at

http://www.hindawi.com

Journal of
Signal Transduction
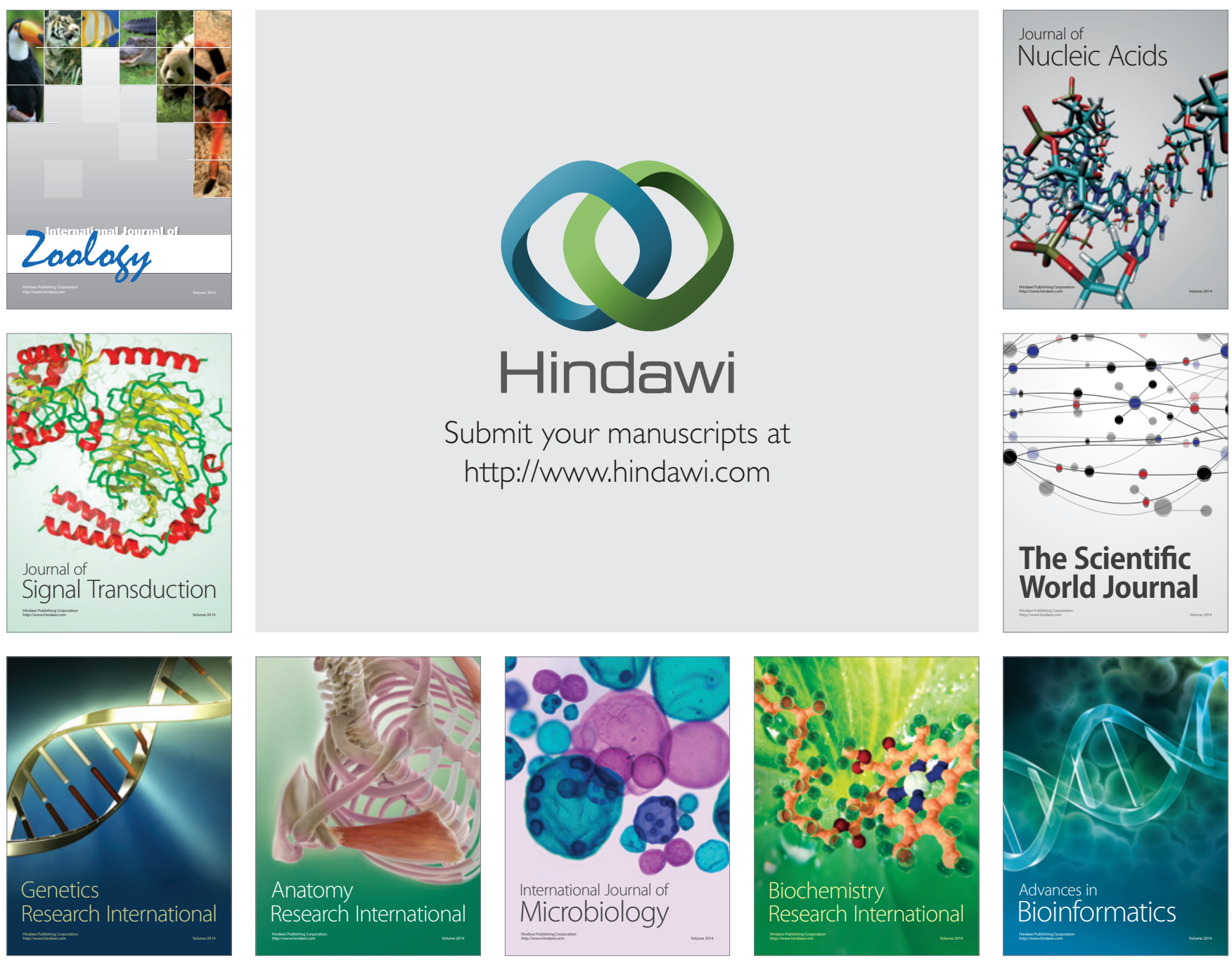

The Scientific World Journal
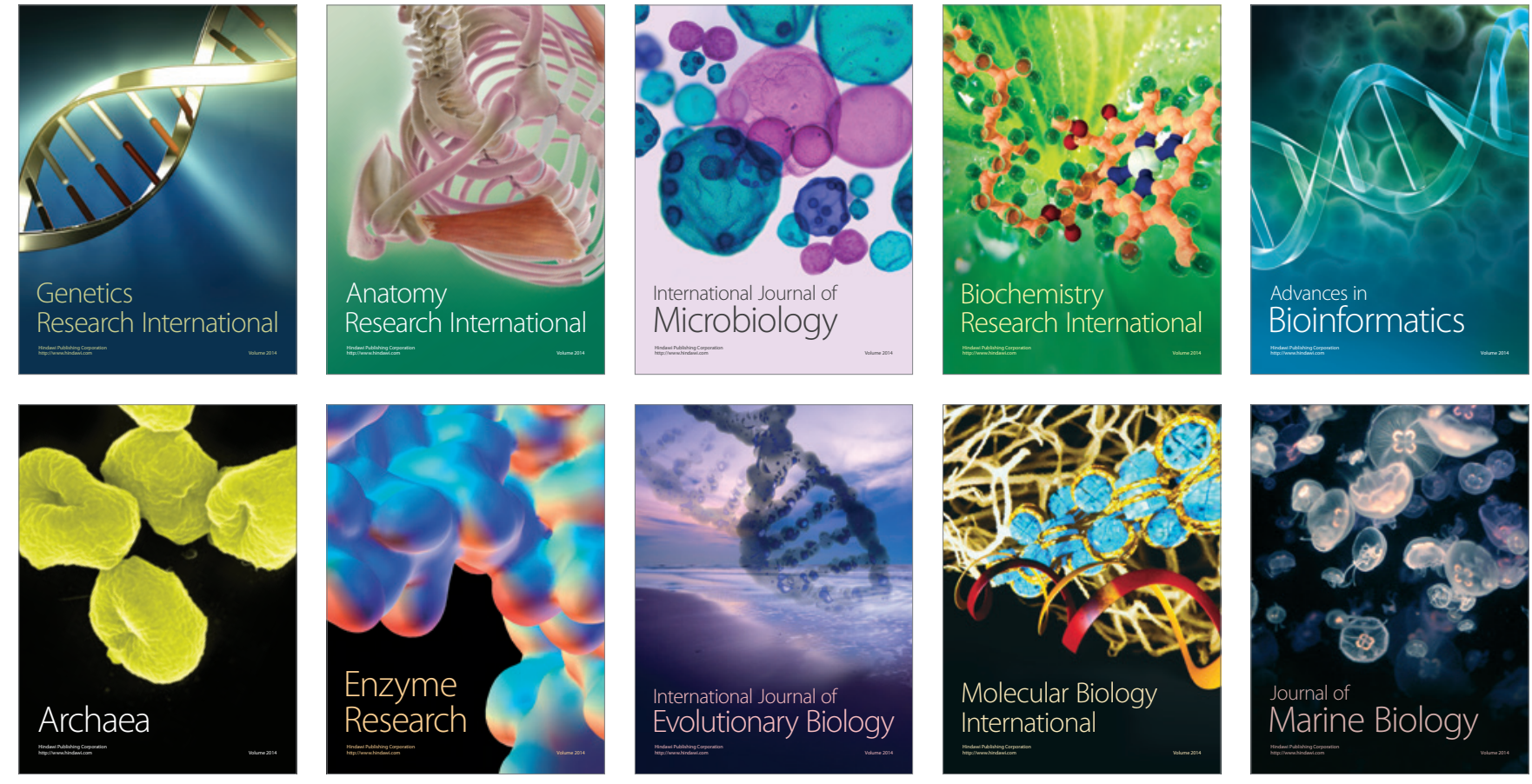